\title{
Os efeitos da produção em blog para sujeitos com Transtorno do Espectro Autista
}

\author{
Ivanise Gomes de Souza Bittencourt $^{1}$, Deise Juliana Francisco ${ }^{2}$ \\ ${ }^{1}$ Escola de Enfermagem e Farmácia- Universidade Federal de Alagoas (UFAL)- \\ Maceió- AL- Brasil \\ ${ }^{2}$ Centro de Educação- Universidade Federal de Alagoas (UFAL)- Maceió- AL- Brasil \\ ivanisegsb@gmail.com,deisej@gmail.com
}

\begin{abstract}
This study, the result of a research Master's in Education, present the effects of production blog for two individuals with Autism Spectrum Disorder (ASD) and was held in the city of Maceió-AL in 2011. The blog became an space expression, appropriation of information and communication technologies and learning of computer resources. The activities provided a shared learning, exchange of experiences, socialization, interaction, improvements in reasoning and communication, rescue of self-esteem, sense of usefulness and satisfaction.
\end{abstract}

\section{Resumo}

Esse estudo, resultado de uma pesquisa de Mestrado em Educação, apresenta os efeitos de produção em blog por dois sujeitos com Transtorno do Espectro Autista (TEA) e foi realizado no município de Maceió-AL em 2011. O blog se constituiu em um espaço de expressão, de apropriação das tecnologias da informação e comunicação e aprendizagem dos recursos informatizados. As atividades proporcionaram uma aprendizagem compartilhada, troca de experiências, socialização, interação, melhorias no raciocínio e comunicação, resgate da auto-estima, sentimento de utilidade e satisfação.

\section{Introdução}

O crescente avanço dos recursos tecnológicos contribui constantemente para aumentar as formas de aprendizagem dos indivíduos. As Tecnologias da Informação e Comunicação (TIC) têm uma influência direta na aquisição de competências e no desenvolvimento das aprendizagens. São estimulantes tanto pela variedade de recursos quanto pela forma como se apresentam.

Destaca-se que os profissionais buscam por informações, métodos e adequações para o atendimento das necessidades dos sujeitos com TEA, anseiam por bons resultados e estão dispostos a trabalhar novas práticas. As TIC apresentam uma possibilidade de inovação dos recursos, numa tentativa de melhorar o desenvolvimento desses sujeitos.

O objetivo do presente estudo foi identificar os efeitos da produção em blog por sujeitos com TEA expondo as potencialidades das tecnologias digitais para o campo do TEA de forma a contribuir com reflexões que possam fazer compreender como o blog pode ser um instrumento relevante de intervenção e aprendizagem para esses sujeitos. 


\section{O sujeito com Transtorno do Espectro Autista}

De acordo com a Lei 12.764 de 27 de dezembro de 2012 que institui a Política Nacional de Proteção dos Direitos da Pessoa com TEA, é considerada pessoa com transtorno do espectro autista aquela portadora de síndrome clínica caracterizada por deficiência persistente e clinicamente significativa da comunicação e da interação social, falência em desenvolver e manter relações apropriadas ao seu nível de desenvolvimento. Por isso, devem ser assegurados às pessoas com TEA os apoios necessários para seu pleno desenvolvimento "por meio de serviços, recursos pedagógicos, tecnologia assistiva, recursos humanos e acesso aos modos e meios de comunicação" (Santos; Silva; Cunha, 2013, p. 126). De maneira que esses sujeitos possam se apropriar tanto dos conhecimentos disponíveis no mundo quanto das formas e das possibilidades de novas produções para uma inserção criativa no mundo (Farias; Maranhão; Cunha, 2008).

Para os diversos profissionais, o TEA representa um desafio, considerando a compreensão inadequada acerca das necessidades dos sujeitos com TEA e a falta de informação sobre suas características leva-os, muitas vezes a serem isolados e até excluídos do convívio nos espaços por onde circulam. A aceitação do diferente é uma barreira a ser vencida com preparação para lidar com a diversidade.

Os recursos tecnológicos têm sido aplicados em sujeitos com TEA, o uso do computador e em especial de ambientes digitais de aprendizagem adaptados aos interesses e necessidades dos sujeitos mostram-se relevantes e importantes no desenvolvimento e interação das pessoas com autismo (Passerino; Santarosa, 2007). Estudos como o de Passerino (2005) propõe uma visão sobre os processos de interação que se estabelecem em ambientes digitais considerando o TEA, onde o uso desses ambientes mostrou-se relevante no desenvolvimento da interação social de sujeitos com autismo. Para Passerino e Santarosa (2007, pg. 63) "é necessário estabelecer estratégias para serem aplicadas em diferentes ambientes educativos de forma que a inserção da tecnologia possa acrescentar o diferencial qualitativo na promoção da interação social de sujeitos com autismo".

Outro estudo de Barbosa (2009) buscou compreender as suas necessidades de formação, as suas dificuldades e identificar possíveis benefícios com o uso das mesmas, procurando também no atual contexto social, softwares e recursos educativos existentes refletindo sobre as implicações destes na evolução social e formativa do autista, propondo aplicações que possam desempenhar um papel importante na resposta a estes desafios, de modo a colaborar para uma possível melhoria da sua qualidade de vida. Esse autor afirma que um ambiente desenvolvido e pensado de acordo com as necessidades específicas destes alunos possibilita uma melhor interação, desenvolvimento cognitivo e aquisição de conhecimentos através do uso das tecnologias. Também defende que "a tecnologia é capaz de complementar e aumentar a qualidade do ensino, contribuindo para a possibilidade da melhoria na comunicação" (Barbosa, 2009, p. 72). Recursos como o computador conjugado a softwares específicos devem ser explorados nesse sentido.

\section{O blog e suas contribuições para o Transtorno do Espectro Autista}

As vantagens do blog são descritas por Oliveira (2006) quanto a uma interface de fácil manuseio, que estimula a criatividade através da escrita livre promovendo a autoria e a co-autoria, possibilita a escrita colaborativa partilhando informações de interesse 
comum, desenvolve a expressão e opinião pessoais, o pensamento crítico e a capacidade argumentativa, desenvolve habilidades e potencializa possibilidades do ensinoaprendizagem.

Igualmente, Pimentel (2009, p. 1) apresenta o blog como "recurso de leitura, escrita e cognição, sendo um espaço democrático de livre expressão [...]", além disso expressa-o como um espaço para o ensino-aprendizagem, exercício da cidadania e como uma poderosa interface comunicacional de múltiplas possibilidades. Para Veen e Vrakking (2009), é possível escrever sobre qualquer coisa, experiências, histórias, convicções, o que desejar compartilhar como o mundo. Com isso, pode representar uma importante ferramenta aos profissionais que atuam junto ao TEA, pois, através da análise desses registros, é possível conhecer ainda sobre os sujeitos e estabelecer as intervenções mais indicadas. Conforme Nascimento, Silva e Mercado (2008) os blogs são um espaço de afirmação de identidade própria e também de liberdade de expressão. Possibilitam, "[...] registrar no mundo virtual as diversas maneiras de ver o mundo real" (Nascimento; Silva; Mercado, 2008, p. 359).

Utilizando o blog, os sujeitos "expressam seus sonhos e ideais, do que gostam de ler, de filmes, religião, da escola, relacionamentos amorosos, em sua maioria, revelando e ocultando suas escolhas, gestos e sensibilidade" (Nascimento; Silva; Mercado, 2008, p. 359). Para Halmann e Bonilla (2009, p. 3), "quanto mais possibilidades proporcionam, mais os sujeitos constituem experiências diversas e ricas de elementos para análise". Através do blog, esses sujeitos encontram um espaço para subjetivação, revelado através das suas escritas. Conforme Gonçalves e Gomes (2014) o uso do blog possibilita um meio de comunicação e interação.

O blog permite momentos de interação, estreitamento de laços e a convivência com as diferenças. Também pode representar uma forma diferente de aprender através do compartilhamento de saberes, proporcionando a valorização dos sujeitos, sua autoestima, crescimento individual e coletivo, e como um meio de inserção social, cidadania e desenvolvimento da autonomia.

As diversas possibilidades de uso da ferramenta blog apontam para a necessidade de exploração das suas contribuições para sujeitos com TEA. Para os sujeitos com TEA, essa ferramenta possibilita a ampliação dos espaços para a autonomia, aprendizagens significativas e exercício da cidadania.

Oportunizar a produção em blog no campo do TEA, através da implantação de oficinas tecnológicas nos serviços de atenção, possibilita aos sujeitos um importante espaço de expressão, comunicação e construção do conhecimento. Permite produções significativas para a sua vida, reflexões, escrever em nome próprio e falar do seu percurso. As construções podem ser amplamente divulgadas e compartilhadas, proporcionando o reconhecimento e valorização desses sujeitos tão incompreendidos, excluídos e discriminados pela sociedade. E por isso, se constituir em um importante dispositivo de habilitação e reinserção social.

Baseado nas questões mencionadas quanto às possibilidades da ferramenta blog para o campo do TEA, apresentam-se os desdobramentos metodológicos que estruturaram uma experiência de produção em blog por sujeitos com TEA. 


\section{Método}

Este estudo é de caráter qualitativo, envolveu uma pesquisa-intervenção e foi realizado em um CAPS localizado no município de Maceió-AL, no período de agosto a dezembro de 2011, totalizando 12 oficinas de produção em blog por sujeitos com TEA. Envolveu a participação da pesquisadora proponente, alunos de graduação em Psicologia e Pedagogia, assistente social do serviço e usuários. Com frequência semanal, às quintasfeiras, das $14 \mathrm{~h}$ às $16 \mathrm{~h}$, permitindo que os sujeitos e equipe interagissem entre si, utilizando-se das tecnologias digitais e potencialidades.

As oficinas terapêuticas informatizadas se constituíram em momentos de interação com o computador e de criação de atividades para o blog. Os recursos computacionais foram utilizados e procurados na medida em que iam sendo solicitados pelas atividades construídas com os usuários no grupo. Em termos de procedimento, as oficinas foram planejadas levando-se em consideração a pedagogia de projetos, em que as atividades são discutidas conjuntamente com usuários e equipe. Os recursos foram apresentados aos participantes (softwares, sua forma de uso) e utilizados na medida em que foram necessários aos projetos individuais. A demanda dos usuários quanto à produção foi atendida, quando os mesmos foram perguntados sobre os conteúdos que gostariam de disponibilizar no blog, bem como a produção da informação (busca de informações, digitação, busca e seleção de imagens, entre outros).

A pesquisa foi realizada mediante o contato direto com dois sujeitos com TEA, com nomes fictícios de "Liga dos Campeões" e "Adele", ambos do sexo masculino, com idades de 24 e 26 anos e um membro da equipe do CAPS, sendo respeitados os procedimentos éticos, estabelecidos na Resolução 466/2012. Os sujeitos assinaram o Termo de Consentimento Livre e Esclarecido (TCLE) e o Termo de Cessão de Direitos de Uso e Divulgação referente à autorização da publicação das produções no blog.

Para a coleta dos dados foram utilizados os prontuários dos sujeitos, a observação participante, a criação de diário de campo e aplicação de entrevistas semiestruturadas. Os prontuários dos sujeitos participantes foram analisados no intuito de coletar informações quanto aos seus históricos de comportamentos e características anteriores ao acompanhamento no CAPS. A observação participante constituiu-se do olhar da pesquisadora proponente dessa pesquisa durante todo o processo e das instruções quanto ao manuseio dos recursos informatizados para o alcance do que fora planejado e idealizado pelos participantes. O diário de campo era realizado pela pesquisadora logo após o término das oficinas através do registro e descrição de todos os acontecimentos da oficina. As entrevistas semi-estruturadas foram realizadas, com os sujeitos e assistente social do serviço durante a etapa de reflexão através do levantamento das informações necessárias para o alcance dos objetivos da pesquisa.

A análise dos dados foi realizada a partir da análise de conteúdo, baseada em Bardin (2011), dos diários de campo, entrevistas, observações e produções postadas no blog a partir das proposições teóricas mencionadas e tendo como foco os objetivos da pesquisa.

\section{Os efeitos da produção em blog por sujeitos com TEA}

\subsection{Liga dos Campeões}


Era um jovem de 24 anos, do sexo masculino. Possuia ensino fundamental incompleto. No início do nosso estudo, apresentava as seguintes características: tranqüilo, receptivo, motivado para as atividades, com entendimento das regras, concentração bastante preservada e problemas no discurso.

Participou de 10 oficinas de blog de um total de 12. Para o blog "Criando Laços", por sugestão dos demais participantes, concordou como nome fíctício "Liga dos Campeões" devido ao seu assunto preferido no momento, permanecendo no decorrer de todas as oficinas.

\section{Produções no blog e os efeitos para Liga dos Campeões}

No início dos trabalhos das oficinas informatizadas, apresentava muitas dificuldades de interação com o grupo e com as atividades propostas, desenvolvendo apenas o que lhe interessava. Por muitas vezes ficava inquieto, não gostando de conviver com as regras estabelecidas. No decorrer dos encontros passou a interagir com o que lhe era proposto e com os demais integrantes. Esteve atento quanto ao que estava sendo produzido pelos colegas e contribuiu para as decisões coletivas. Desenvolveu a participação e o interesse em aprender cada vez mais com o que o grupo tinha a lhe oferecer.

Em sua página, podemos visualizar inicialmente o seu avatar e uma imagem do CSKA, um dos seus times preferidos, figura 1:

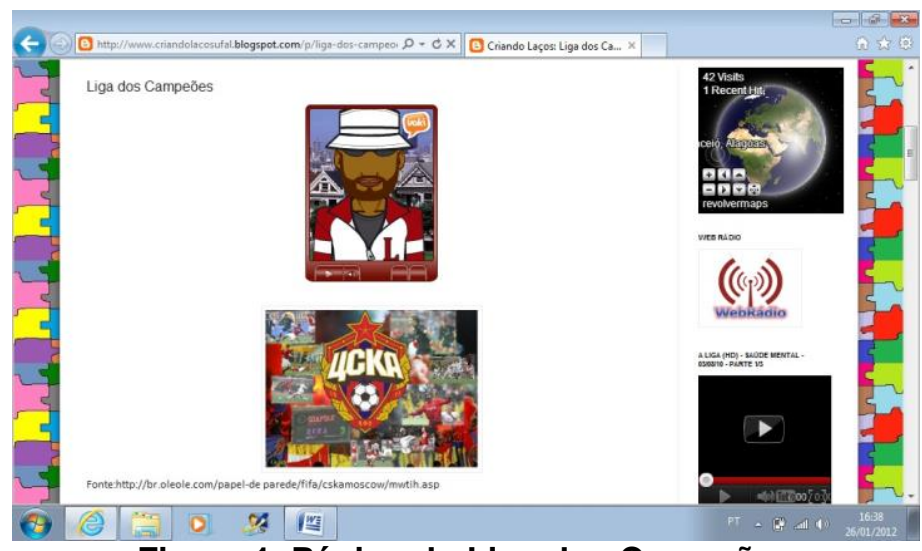

Figura 1. Página do Liga dos Campeões Fonte: www.criandolacosufal.blogspot.com

O blog se constituiu em um espaço para sua escrita e cognição, conforme apresentou Pimentel (2009) e como um meio para a sua comunicação, democratização de idéias e informações de acordo com Trindade e Becker (2011). No caso de Liga dos Campeões, ele escolheu uma temática de seu interesse para socializar e apresentar informações sobre futebol. Produziu sua página pelo prazer de compartilhar as informações, como disse Orihuela (2007), do mundo futebolístico.

A participação no grupo favoreceu o seu desenvolvimento cognitivo, pois passou a compreender melhor as atividades e a se expressar nos grupos de reflexões se colocando quanto ao que achava do processo, desenvolvendo a sua capacidade argumentativa de acordo com Oliveira (2006). Quanto ao que sentia com a sua página no blog, respondeu: "Adorei ver a Liga dos Campeões". 
A sua prática para a produção possibilitou sua autonomia e o exercício do pensamento e da memória, mostrando-se como um ser vivo potente, de acordo com Francisco e Renz (2010), apesar das suas limitações. Estimulou a sua criatividade e desenvolveu aprendizagem, como disse Oliveira (2006). Estruturando o blog, pôde revelar as suas escolhas, conforme Nascimento, Silva e Mercado (2008) enfatizaram. Quanto ao que sentiu enquanto um dos produtores do blog, respondeu: "Gosto porque digitei". Quanto ao que o blog representava para ele declarou: "Eu me sinto alegre". As atividades do projeto e do grupo causaram efeito no seu problema com o discurso, houve um significativo progresso na sua forma de comunicação.

\subsection{Adele}

Era um jovem de 26 anos, sexo masculino. Possuia ensino médio completo. No início deste estudo, apresentava as seguintes características: pouca interação, muito parado, cabisbaixo, sem olhar nos olhos das pessoas e só respondia perguntas quando perguntado duas ou três vezes e de forma bem curta, com uma única palavra.

Participou de 10, das 12 oficinas de blog. Para o blog "Criando Laços", escolheu como nome fictício "Adele" que é o nome de uma cantora internacional que gosta muito.

\section{Produções no blog e os efeitos para Adele}

Aos poucos foi demonstrando alegria e satisfação em participar das atividades e por estar em contato com o grupo, basicamente o seu único momento para interação com outras pessoas além dos pais. Passou a se comunicar mais através da convivência no grupo.

Em sua página, podemos visualizar inicialmente o seu Avatar e uma imagem do cantor Renato Russo, um dos seus músicos preferidos, a qual pesquisou na internet, como podemos ver na figura 2 :

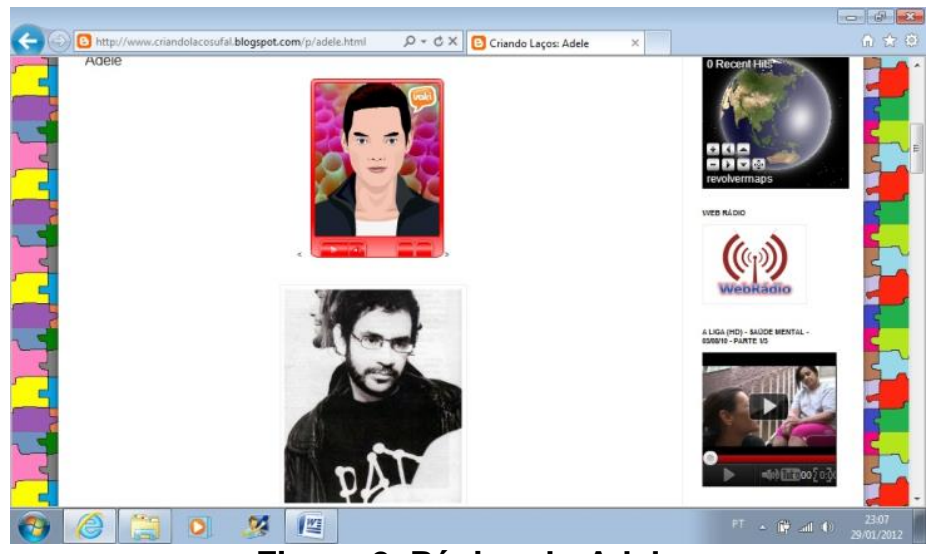

Figura 2. Página do Adele

Fonte: www.criandolacosufal.blogspot.com

Sua participação no grupo lhe proporcionou uma interação satisfatória com as atividades e com os outros participantes, de acordo com Pocho et al (2010). Desenvolveu a comunicação, conforme Trindade e Becker (2011), a qual se encontrava prejudicada permitindo-se uma postura menos introvertida. 
Quando perguntado como se sentia participando das oficinas informatizadas, escreveu: "Bem. I Feel Cool :)". Sobre o que sentia com o blog, revelou: "Feliz que o blog se iniciou". Quanto as suas produções escreveu: "É legal pôr as coisas que você gosta no blog:)".

Enquanto um dos produtores do blog desenvolveu a sua autonomia (Oliveira; Fortunato, 2007). O que podemos identificar em sua fala quanto às contribuições desse blog na sua vida: "É legal construir laços com outras pessoas, estudantes da UFAL". Como também declarou o que o blog representava para ele: "Representa laços de amizade com os estudantes da UFAL". Igualmente ao estudo de Francisco (2009) o fato do projeto estar vinculado a universidade, produziu uma inserção ao meio acadêmico.

Assim, pode-se perceber, apesar das diferentes demandas dos participantes e de suas produções no blog (futebol e música, por exemplo), o movimento de discussão com os demais participantes, a busca pela aprendizagem sobre os softwares, possibilitou uma maior expressão verbal. Esta foi analisada a partir dos dados do diário de campo, em que se verificou o aumento das interações dos participantes da pesquisa entre si e com a equipe, quanto à quantidade e qualidade. Isso auxiliou a produção do blog. $\mathrm{O}$ componente visual do blog, facilitou a expressão dos participantes da oficina, tendo em vista que foi uma das formas mais escolhidas (uso de imagens). Também a expressão espontânea de temas de interesse e habilidades socioemocionais, com avanço no autoconhecimento e na seleção de preferências.

\section{Considerações Finais}

Através das oficinas de blog, os sujeitos com TEA obtiveram conhecimento sobre essa ferramenta e suas formas de manuseio, além da aprendizagem dos recursos informatizados. O blog se constituiu em um espaço de expressão sobre o que era significativo para eles de autonomia e demonstração das suas capacidades e potencialidades. As atividades proporcionaram uma aprendizagem compartilhada, troca de experiências, socialização, interação, companheirismo, satisfação e o fortalecimento dos laços entre todos os participantes. Promoveram novos modos de vida, novas relações com eles mesmos, com os demais integrantes e uma nova maneira de se relacionar com a sua própria família.

Oportunizar a autoria em blog nesse campo do TEA possibilita aos sujeitos um importante espaço de expressão, comunicação e construção do conhecimento. Permite produções significativas para a sua vida, reflexões, escrever em nome próprio e falar do seu percurso. As construções podem ser amplamente divulgadas e compartilhadas, proporcionando o reconhecimento e valorização desses sujeitos. E por isso, se constituir em um importante dispositivo para a reinserção social. Além de contribuir no processo de ensino/aprendizagem dos sujeitos com TEA, onde o processo de escolarização ainda está em construção e em ressignificação de práticas.

Apesar deste ser um estudo qualitativo, sem vistas de generalização dos dados, pode-se refletir sobre a oportunidade de utilizar os recursos da TIC na educação de pessoas com TEA, na perspectiva de construção de espaço de expressão, comunicação e construção do conhecimento. Houve, no estudo a produção significativa para a vida pessoal, a escrita em nome próprio e o relato do percurso. Com o blog pode-se divulgar e compartilhar as produções, proporcionando o reconhecimento e valorização dos 
CBIE-LACLO 2015

Anais do XXVI Simpósio Brasileiro de Informática na Educação (SBIE 2015)

sujeitos como produtores de informação. Ao falarmos sobre educação, estes princípios são relevantes.

\section{Referências}

Barbosa, H. F. (2009). Análise do recurso a novas tecnologias no ensino de autistas. Dissertação de Mestrado em Engenharia Informática- Sistemas Gráficos e Multimédia do Instituto Superior de Engenharia do Porto- Portugal. Disponível em: http://recipp.ipp.pt/bitstream/10400.22/3079/1/DM_HugoBarbosa_2009_MEI.pdf. Acesso em: 28 dez. 2013.

Bardin, L. (2011)Análise de conteúdo. São Paulo: Edições 70.

Brasil. (2012). Lei $n^{o} 12.764$ de 27 de dezembro de 2012. Disponível em: http://www.planalto.gov.br/ccivil_03/_ato2011-2014/2012/lei/112764.htm. Acesso em: 25 dez. 2013.

Farias, I. M.; Maranhão, R. V.; Cunha, A. C. (2008). Interação professor-aluno com autismo no contexto da educação inclusiva: análise do padrão de mediação do professor com base na teoria da Experiência de Aprendizagem Mediada (Mediated Learning Experience Theory). Rev. bras. educ. espec. vol.14 no.3 Marília Sept./Dec. Disponível em: http://www.scielo.br/pdf/rbee/v14n3/v14n3a04.pdf. Acesso em: 25 dez. 2013.

Francisco, D. J.; Renz, J. P. (2010). Relação homem-máquina: pessoas em sofrimento psíquico e recursos digitais. Scientia Plena, v. 6, n. 11. Disponível em: http://www.scientiaplena.org.br/ojs/index.php/sp/article/viewFile/179/69. Acesso em: 20 abr. 2011.

(2009). Inclusão digital: reflexões em saúde mental. Revista Edapeci: educação a distância e práticas educativas comunicacionais e interculturais. n.1. Disponível em: http://www.edapeci-ufs.net/revista/ojs-2.2.3/index.php/edapeci. Acesso em: 25 ago. 2010.

Gonçalves, F. C.; Gomes, N. S. (2014). Novas tecnologias e ensino em Campo Grande: um panorama do uso do blog nas escolas públicas da capital de Mato Grosso do Sul. Anais do III Congresso Brasileiro de Informática na Educação (CBIE 2014) e XXV Simpósio Brasileiro de Informática na Educação (SBIE 2014).

Halmann, Adriane L.; Bonilla, Maria H. (2009). Diários da prática docente em blogs: aspectos da reflexão entre professores. Associação Nacional de Pós-Graduação e Pesquisa em Educação- Anped. Disponível em: http://www.anped.org.br/reunioes/32ra/arquivos/trabalhos/GT16-5866--Int.pdf. Acesso em: 03 ago. 2011. 
Nascimento, E. F.; Silva, L. R.; Mercado, L. P. (2008). Uso do blog na prática pedagógica. In. MERCADO, Luís P. (Org.). Práticas de formação de professores na educação à distância. Maceió: Edufal.

Neves, G. V.; Boeira, A. F. (2010). Blogs como estratégia pedagógica na aprendizagem de estudantes surdos: possibilidades e desafios. Anais do XV ENDIPE - Encontro Nacional de Didática e Prática de Ensino: convergências e tensões no campo da formação e do trabalho docente: políticas e práticas educacionais, Belo Horizonte.

Oliveira, F. B.; Fortunato, M. L. (2007). Reabilitação psicossocial na perspectiva da reforma psiquiátrica. Vivência, n. 32. Disponível em: http://www.cchla.ufrn.br/vivencia/sumarios/32/PDF\%20para\%20INTERNET_32/C AP\%2010_FRANCISCA\%20BEZERRA_E_MARIA\%20LUCINETE.pdf. Acesso em: 07 jan. 2012.

Oliveira, R. M. (2006). Aprendizagem mediada e avaliada por computador: a inserção dos blogs como interface na educação. In. SILVA, Marco e SANTOS, Edméa (Org.). Avaliação da aprendizagem em educação online: fundamentos, interfaces e dispositivos, relatos de experiências. São Paulo: Loyola, p.333.

Orihuela, J. L. (2007). Blogs e blogosfera: o meio e a comunidade. In: ORDUÑA et al (Orgs.). Blogs: revolucionando os meios de comunicação. São Paulo: Thomson Learning, p.1.

Passerino, L. M. (2005). Pessoas com autismo em ambientes digitais de aprendizagem: estudo dos processos de interação social e mediação. Tese de Doutorado do Programa de Pós-Graduação em Informática na Educação da Universidade Federal do Rio Grande do Sul. Disponível em: http://www.lume.ufrgs.br/bitstream/handle/10183/13081/000634298.pdf?sequence=1 . Acesso em: 26 dez. 2013.

; Santarosa, L. C. (2007). Interação social no autismo em ambientes digitais de aprendizagem. Psicol. Reflex. Crit. [online], vol.20, n.1, pp. 54-64. Disponível em: http://www.scielo.br/pdf/prc/v20n1/a08v20n1.pdf. Acesso em: 26 dez. 2013.

Pimentel, F. S. (2009). Da pessoalidade para a formação cidadã de alunos: a experiência de um blog como espaço democrático. Debates em Educação. v 01. n. 2, Jul./Dez. Disponível em: http://www.seer.ufal.br/index.php/debateseducacao/article/view/37/46 Acesso em: 10 de mai. 2011.

Pocho et al. (2010). Tecnologia educacional: descubra suas possibilidades na sala de aula. 5. ed. Petrópolis: Vozes.

Santos, M. C.; Silva, R. C.; Cunha, P. (2013). Política nacional da educação especial na perspectiva da educação inclusiva. In: Linha de cuidado para a atenção às pessoas com Transtornos do Espectro do Autismo e suas famílias na Rede de Atenção Psicos- 
CBIE-LACLO 2015

Anais do XXVI Simpósio Brasileiro de Informática na Educação (SBIE 2015)

social do SUS. Brasília: Ministério da Saúde. Disponível em:

http://www.autismo.org.br/site/images/Downloads/linha_cuid_autismo.pdf. Acesso em: 25 dez. 2013.

Trindade, C. O.; Becker, A. M. (2011). Aprendizagem colaborativa mediada pelo blog do moodle. Anais do VIII Encontro Virtual de Documentação em Software Livre e Congresso Internacional de Linguagem e Tecnologia online - EVIDOSOL/V CILTEC-online. V. 1, n. 1, junho. Disponível em: http://www.textolivre.org/viiievidosol/forum/90.pdf. Acesso em: 15 nov. 2011.

Veen, W.; Vrakking, B. (2009). Homo zappiens: educando na era digital. Porto Alegre: Artmed. 